Harmoko, Eka Lokaria, Ade Dea Sintya. (2018). Eksplorasi Mikroalga di Air Terjun Temam Kota Lubuklinggau, Provinsi Sumatera Selatan. Jurnal Bioeksperimen. Vol. 4 (2) Pp. 75-80. Doi: 10.23917/bioeksperimen.v4i1.2795

\title{
EKSPLORASI MIKROALGA DI AIR TERJUN TEMAM KOTA LUBUKLINGGAU, PROVINSI SUMATERA SELATAN
}

\author{
Harmoko', Eka Lokaria ${ }^{2),}$ dan Ade Dea Sintya ${ }^{2)}$ \\ ${ }^{1)}$ dan ${ }^{2)}$ Dosen Pendidikan Biologi STKIP-PGRI Lubuklinggau, Lubuklinggau \\ ${ }^{2)}$ Mahasiswa Pendidikan Biologi STKIP-PGRI Lubuklinggau, Lubuklinggau \\ Jl. Mayor Toha, Kel. Air Kuti, Kota Lubuklinggau Kode Pos 31626 \\ e-mail: putroharmoko@gmail.com
}

\begin{abstract}
Abstrak
Sampai saat ini ditemukan penelitian yang membahas tentang berbagai jenis mikroalga di air terjun Temam Lubuklinggau kota. Penelitian ini bertujuan untuk mengeksplorasi jenis-jenis mikroalga di kota Temam Lubuklinggau air terjun. Metode yang digunakan adalah survei. Teknik pengumpulan data dalam penelitian ini dengan observasi lapangan kerja. Teknik analisis data adalah deskriptif kualitatif. Hasil penelitian menunjukkan identifikasi mikroalga di air terjun Teman Lubuklinggau kota ditemukan 17 Genus dari 4 divisi mikroalga. Mikroalga yang terdiri dari divisi Chlorophyta 7 genus yaitu: Spirogyra, ulothrix, Gonium, Microspora, Closterium, Cosmarium, Desmidium, Divisi Xanthophyta 1 genus, yaitu: Tribonema, Divisi Crysophyta 1 genus, yaitu: Chromulina dan divisi Bacillariophyta 8 genus yaitu: Guinardia, Tabellaria, Eunotia, Asterionella, Frustulia, Surirella, Synedra, dan Navicula. Sedangkan data endukung mengamati bahwa $p H$ dan subu. Kesimpulan dari penelitian ini adalah: mikroalga yang berhasil diidentifikasi di air terjun Temam Lubuklinggau terdiri dari 4 divisi dan 17 genus.
\end{abstract}

Kata kunci: Eksplorasi, Mikroalga, Air Terjun Temam, Lubuklinggau

\section{Pendahuluan}

Indonesia adalah salah satu negara di dunia yang memiliki ekosistem perairan yang cukup luas. Provinsi Sumatera Selatan merupakan daerah yang memiliki ekosistem perairan yang cukup beragam, mulai dari danau, waduk, irigasi, sungai, rawa dan air terjun. Salah satu air terjun yang terletak di Sumatera Selatan adalah Air Terjun Temam, yang berada di kota Lubuklinggau, dan merupakan salah satu tujuan wisata potensial (Naib, 2015:04).

Jumlah kunjungan wisatawan ke objek wisata di kota Lubuklinggau pada tahun 2014 sebanyak 150.306 orang (BAPEDA Lubuklinggau, 2016:74). Air terjun Temam memiliki banyak keanekaragaman hayati. Salah satu contohnya adalah ganggang mikroskopik. Hingga saat ini sudah ditemukan penelitian terkait jenis-jenis mikroalga di air terjun Temam, Lubuklinggau.
Mikroalga meruakan fotositetik mikroorganisme air mikroskopik, yang dapat ditemukan di air tawar dan air laut, (Winahyu, 2013) dan termasuk ke dalam bentuk fotoautotrof (Pratiwi, 2008:46). Ganggang memainkan peran sebagai salah satu parameter ekologis yang dapat memberikan gambaran tentang perairan negara dan termasuk komponen biotik penting dalam metabolisme tubuh air, karena ini merupakan mata rantai utama dalam rantai makanan ekosistem akuatik (Ocean et al, 2012).

\section{METODE PENELITIAN}

\section{Jenis penelitian Jenis penelitian}

Jenis penelitian ini adalah penelitian survei yang menggambarkan objek yang diteliti dengan mengambil sampel di air terjun Temam kemudian mengukur parameter kualitas air dan mengindentifikasinya untuk 
melihat semua jenis mikroalga yang hidup di air terjun Temam. Stasiun sampling terdiri dari tiga stasiun, yaitu aliran di atas air terjun, bagian bawah air terjun, dan aliran airnya serta setiap stasiun terdiri dari tiga titik sampling.

\section{Alat dan bahan}

Alat yang digunakan dalam penelitian ini adalah sebagai berikut: planktonnet, mikroskop, kaca benda, kaca penutup, botol, plastik, karet gelang, pipet, gelas kimia, kamera, label, pena, buku, meteran, kapas, $\mathrm{pH}$ meter dan termometer. Bahan yang digunakan dalam penelitian ini adalah sebagai berikut: sampel air terjun Temam, Alkohol 70\%, dan Formalin

\section{Tahap Pelaksanaan}

a. Sampling terdiri dari 9 titik di lokasi pengamatan air terjun Temam sampel diambil pada pagi hari dengan pengulangan selama 3 kali.

b. Pengambilan sampel dengan penyaringan menggunakan jaring planktonnet.

c. Sampel diambil dan kemudian dimasukkan dalam botol dan diberikan label.

d. Kemudian sampel dibawa ke laboratorium Biologi STKIP-PGRI Lubuklinggau untuk diamati.

e. Sampel air diambil dengan menggunakan pipet dan dijatuhkan ke dalam objek kaca yang sebelumnya telah dibersihkan dengan alkohol $70 \%$ dan ditutup dengan tutup kaca.

f. Kemudian ditempatkan dalam miskroskop untuk diamati dan diidentifikasi.

\section{Teknik Pengumpulan Data}

Sampleof mikroalga diamati dengan menggunakan mikroskop dan kemudian diidentifikasi dengan cara mencocokkan gambar yang diperoleh dengan literatur Biggs dan Kilory (2000), Botes (2003) dan Bellinger dan Sigee (2010).

\section{Teknik Analisis Data}

Data yang diperoleh dan dianalisis secara deskriptif kualitatif. Setelah mikroalga teramatai, langkah selanjutnya adalah mengidentifikasi spesies dan klasifikasinya. Juga perlu untuk mengidentifikasi sifatcirimya.

\section{Hasil dan Pembahasan}

\section{Hasil}

Hasil eksplorasi mikroalga di air terjun Teman Kota Lubuklinggau menemukan 4 Divisi 4 Kelas 15 Ordo dan 17 Genus. Mikroalga ditemukan di Air Terjun Temam Lubuklinggau, dapat dilihat pada Tabel 1. 
Tabel 1. Klasifikasi mikroalga di Air Terjun Temam Lubuklinggau

\begin{tabular}{|c|c|c|c|c|}
\hline No & Divisi & Kelas & Order of & Genus \\
\hline \multirow{7}{*}{1.} & \multirow{7}{*}{ Chlorophyta } & \multirow{7}{*}{ Chlorophyta } & Zygnematales & Spirogyra \\
\hline & & & Ulotricales & Ulothrix \\
\hline & & & Volvocales & Gonium \\
\hline & & & Microsporales & Microspora \\
\hline & & & \multirow{2}{*}{ Desmidales } & Closterium \\
\hline & & & & Cosmarium \\
\hline & & & Zygnemetales & Desmidium \\
\hline 2. & Xanthophyta & Xanthophyceae & Tribonematales & Tribonema \\
\hline \multirow{8}{*}{3.} & \multirow{8}{*}{ Bacillariophyta } & \multirow{8}{*}{ Bacillariophyceae } & Biddulphiales & Guinardia \\
\hline & & & Tabellariales & Tabellaria \\
\hline & & & \multirow{2}{*}{ Eunotiales } & Eunotia \\
\hline & & & & Asterionella \\
\hline & & & \multirow{2}{*}{ Naviculales } & Frustulia \\
\hline & & & & Navicula \\
\hline & & & Surirellales & Surirella \\
\hline & & & Fragilariales & Synedra \\
\hline 4. & Crysophyta & Chrysophyceae & Chrysophyceae & Chromulina \\
\hline
\end{tabular}

\section{Pembahasan}

Pengamatan spesies mikroalga di air terjun Temam Lubuklinggau dilakukan dengan membandingkan karakteristik morfologi antara hasil penelitian dengan mengidentifikasi buku dan literatur sebagai referensi. Literatur yang digunakan adalah Biggs dan Kilory (2000), Botes (2001) dan Bellinger dan Sigee (2010).

Pengamatan dilakukan 3 pengulangan dan berhasil mengidentifikasi empat divisi: divisi Chlorophyta, divisi Xanthophyta, divisi Bacillariophyta dan divsi Crysophyta. Divisi Chlorophyta memiliki karakteristik struktur tubuh ganggang hijau bervariasi dari sel tunggal, membentuk koloni multisel hingga filamen. Sebagian besar organisme ini mengandung kloroplas di setiap sel satu yang mengandung pusat pembentukan pati yang disebut pirenoid. Dinding sel terbuat dari selulosa (Pratiwi, 2008:53).

Genus kelas Bacillariophyceae ditemukan dalam jumlah yang lebih besar karena ganggang kelompok ini memiliki kemampuan untuk menempel substrat Andriansyah et al (2014). Welch (1980) menyatakan Bacillariophyceae bahwa kelasadalah kelas yang paling sering mendominasi di sungai dan kelimpahannya sangat tinggi, kecuali di sungai berlumpur.

Pembagian Xanthophyta ganggang hijau kuning, dan menggambarkan keadaan antara Chrysophyta dan Chlorophyta. Sel-sel motil dengan dua flagela yang tidak lagi sama. Sek dinding sering mengandung silika. Umumnya, sel-sel adalah uniseluler, membentuk koloni, berserabut atau tubular, (Pratiwi, 2008:53).

Divisi Crysophyta adalah sejenis ganggang yang berwarna coklat keemasan. Sel yang berwarna keemasan sampai kuning kecoklatan tergantung pada dominasi pigmen tambahan. Sel Crysophyta berbentuk bulan dan kadang terus berkembang biak dalam bentuk matriks massa yang disebut bergelatin palmeloid. Umumnya Chrysophyta motile dan mimiliki satu atau dua flagela yang panjangnya tidak sama (Pratiwi, 2008: 52). 
Divisi alga mikroskopis ditemukan di air terjun Temam Lubuklinggau kota divisi, Xanthophyta Bacillariophyta, Chlorophyta dan Crysophyta sesuai dengan tempat pertumbuhanya yang merupakan spesies yang hidup di air tawar.

Divisi yang mendominasi dan bervariasi dalam setiap sampel jatuh temam adalah divisi Bacillariophyta yang terdiri dari 8 genus, dan yang paling rendah ditemukan divisi Crysophyta dan divisi Xanthophyta hanya ditemukan 1 ordo. Meskipun Xanthophyta hanya terdiri dari 1 genus Tribonema. Tribonema yang paling umum ditemukan di setiap sampel air terjun Temam Lubuklinggau.

Berbagai jenis mikroalga yang ditemukan di air terjun Temam kota Lubuklinggau bagian atas terdiri dari Spirogyra, ulothrix, Gonium, Closterium, Cosmarium, Desmidium, Tribonema, Guinardia, Tabellaria, Eunotia, Frustulia, Surirella, Synedra, Navicula, dan Chromulina.

Sedangkan jenis mikroalga yang ditemukan di air terjun Temam kota Lubuklinggau bagian bawah terdiri dari Spirogyra, ulothrix, Gonium, microspora, Closterium, Cosmarium Desmidium, Tribonema, Tabellaria, Asterionella, dan Navicula.

Tidak terlalu banyak jenis mikroalga yang berbeda yang ditemukan di bagian atas dan bawah karena lokasi pengambilan sampel pengamatan air terjun Temam adalah air yang memiliki satu aliran arus masuk dan keluar, tetapi ada beberapa jenis yang hanya ditemukan di bagian atas saja. dan ada beberapa jenis yang ditemukan di bagian bawah saja, karena perbedaan letak bagian atas kondisi air dangkal lebih baik daripada bagian bawah.

Menurut Prihantini (2008:53) menyatakan bahwa transparansi air adalah suatu kondisi yang menggambarkan kemampuan penetrasi sinar matahari untuk menembus lapisan air hingga kedalaman tertentu, dan lokasi teratas ada lebih banyak batuan. Batu adalah salah satu habitat mikroalga sehingga lebih banyak jenis mikroalga yang ditemukan di bagian atas (Pratama, 2008:53).
Jenis mikroalga yang ditemukan di air terjun Temam Lubuklinggau kota pada minggu pertama di divisi Chlorophyta adalah Spirogyra, ulothrix, Gonium, dan microspora. Atdivisi Xanthophyta bahwa Tribonema dan pembagian Bacillariophyta adalah jenis Surirella dan Synedra.

Pada minggu kedua spesies mikroalga ditemukan di air terjun Temam Lubuklinggau kota di divisi Chlorophyta adalah Spirogyra, ulothrix, Gonium, Closterium, Cosmarium dan Desmidium, dan ada jenis baru dari genus yang tidak diketahui. Indivision Xanthophyta hanya Tribonema ditemukan, dan divisi Bacillariophyta di minggu kedua menemukan empat jenis ganggang yang berbeda dari minggu pertama yang Guinardia, Tabellaria, Eunotia, dan Asterionella.

Pada minggu ketiga ditemukan spesies mikroalga yang ditemukan di air terjun Temam Lubuklinggau kota di divisi Chlorophyta tidak berubah dari minggu pertama dan minggu kedua hanya pada minggu ketiga jenis microspora tidak ditemukan.

Dalam pembagian Xanthophyta jeni stidak ditemukan perubahan dari minggu pertama dan kedua hanya ada satu jenis pembagian Xanthophyta yaitu Tribonema, dan pada divisi Bacillariophyta menemukan Tabellaria, Eunotia, Asterionella, Surirella, Synedra dan menemukan strain ganggang belum ditemukan pada minggu pertama dan yang kedua di Xanthophyta divisi, yaitu Frustulia dan Navicula. Pada minggu ketiga ditemukan divisi baru di divisi Crysophyta yaitu Chromulina. Jenis mikroalga yang didapat adalah organisme yang mengapung di air dan bergerak dengan arus yang memiliki batas toleransi lingkungan.

Batas toleransi terhadap perubahan lingkungan bervariasi tergantung pada masingmasing organisme. Batas toleransi terhadap $\mathrm{pH}$ organisme hidup bervariasi dan dipengaruhi, antara lain, suhu, oksigen terlarut, jenis organisme dan kehidupan. Parameter yang diukur dalam penelitian ini adalah $\mathrm{pH}$ dan suhu, di air terjun kota Temam Lubuklinggau. 
Parameter kualitas air merupakan faktor yang tidak kalah pentingnya jika kualitas airnya optimal maka dapat hidup dengan mikroalga stabil. Setelah pengukuran nilai $\mathrm{pH}$ diperoleh selama minggu pertama 8,6 minggu kedua 8,9 dan minggu ketiga 9,0. Menurut Rukminasari (2014:28) perubahan $\mathrm{pH}$ tinggi dan rendah yang diinduksi oleh fluktuasi kandungan $\mathrm{O}_{2}$ dan $\mathrm{CO}_{2}$ dalam air, dan diperoleh nilai $\mathrm{pH}$ rata-rata 8,83 dapat dikatakan produktif karena menurut Pratama (2008:49) rentang $\mathrm{pH}$ optimum 4- 11.

Kemudian didukung oleh pendapat Odun (dalam Junda, 2012:114) menyatakan batas toleransi organisme di perairan dengan $\mathrm{pH}$ antara 6-9 adalah perairan dengan kesuburan tinggi dan relatif tidak produktif karena memiliki Kisaran $\mathrm{pH}$ yang dapat mendorong proses pembongkaran bahan organik yang ada di air menjadi mineral yang berasimilasi oleh ganggang mikroskopik yang mengambang merupakan bagian dari fitoplankton.

Selain $\mathrm{pH}$, suhu juga mempengaruhi keberadaan mikroalga. Setelah pengukuran nilai suhu yang didapat Temam mengamati air terjun adalah $26^{\circ} \mathrm{C}$, dengan suhu $26^{\circ} \mathrm{C}$, dapat dikatakan bahwa suhu yang relatif normal untuk pertumbuhan mikroalga.
Menurut Pelczar (2013:246) suhu optimum untuk produktivitas mikroalga di perairan berkisar antara $20-30^{\circ} \mathrm{C}$, dari jenis mikroalga yang ditemukan di air terjun Temam Lubuklinggau kota yang didukung oleh penilitian Junda (2013:22) menyatakan bahwa kelas Bacillariophyceae dan Chlorophyceae cenderung lebih umum dan kondisi kehidupan yang stabil.

Mikroalga dari filum Chlorophyta dan diatom akan tumbuh dengan baik dalam kisaran suhu berturut-turut $30^{\circ} \mathrm{C}-35^{\circ} \mathrm{C}$ dan $20^{\circ} \mathrm{C}-30^{\circ} \mathrm{C}$, dan dikuatkan oleh hasil penelitian Prihantini (2008:52) menambahkan bahwa suhu adalah secara langsung berpengaruh dalam mengontrol laju berbagai proses metabolisme di sel mikroalga.

\section{Simpulan}

Berdasarkan penelitian yang telah dilakukan dapat disimpulkan bahwa hasil identifikasi mikroalga di air terjun Teman Kota Lubuklinggau, terdiri dari Spirogyra, Ulothrix, Gonium, Microspora, Closterium, Cosmarium, Desmidium, Tribonema, Chromulina, Guinardia, Tabellaria, Eunotia, Asterionella, Frustulia, Surirella, Synedra dan Navicula.

\section{Daftar Pustaka}

Andriansyah., Tri, R.S, dan Irwan, L. (2014). Kualitas Air Sungai Jawi dan Sungai Raya di Kota Pontianak Dilihat dari Struktur Komunitas Mikroalga Perifitik. [Versi elektronik]. Jurnal. Protobiont 2014 Vol 3 (1): halaman61-70.

Badan Perencanaan Pembangunan Daerah. (2016). Kerja Pemerintah Daerah. PemerintahRencanaLubuklinggau: Lubuklinggau

Bellinger, E. G., \& Sigee, D. C. 2010. Freshwater Algae Identification and Use as Bioindicators. London: Wiley Blcakwell.

Biggs, BJF \& Kilroy, C. (2000). Pemantauan Aliran Periphyton Manual.Diterbitkan oleh Niwa For MFE.

Botes.L. (2001). Phytoplankton Identification Catalogue. South Africa, Glaballast Monograph.

Junda, M., Hasrah., Dan Hala, Y. (2012). Identifikasi Genus Fitoplankton Dalam Satu Udang di Desa Kecamatan Bontomate'ne Segeri Pangkep. [Versi E-lectronic] BionatureJournal, 13, 108-115.

Junda, M., AH., Dan Hala, Y. (2013). Identifikasi perifiton Menentukan Kualitas Udara di Tambak 
Ikan Nila (Oreochromis niloticus). [Versi E-lectronic] Jurnal Bionature, 15, 16-24.

Naib, A. (2015). Pangkalan Data Pariwisata Lubuklinggau,2015.Pariwisata Biro Lubuklinggau: Lubuklinggau.

Pelczar, M.J (2013). Dasar-dasar Mikrobiologi. University of Indonesia: Jakarta.

Pratiwi, S. (2008). Mikrobiologi Farmasi. Jakarta: Erlangga.

Prihantini, B.N, Vishnu, W., \& Dian, H. (2008). Cyanobacteria biodiversity dari beberapa Situ/ Danau di Jakarta Pusat-Depok-Bogor, Indonesia. [Versi elektronik]. MakaraS cience, 12, 44-54.

Samudra, S.R., Tri, R.S dan Munifatul, I. (2012). Komposisi, Kemelimpahan dan Keanekaragaman Fitoplankton Danau Rawa Pening Kabupaten Semarang. J. Bioma. Vol. 15 No 1. Hal 7.

Winahyu, D.A, Yulistia, A., Elly, L., Rustiati., Jani, M., \& Andi, S. (2013). Studi Awal Tentang Keanekaragaman Mikroalga di Pusat Konservasi Gajah, Taman Nasional Way Kambas. Prosiding Semirata Universitas Negeri Lampung.

Welch, E.B. (1980). Efek Ekologis dari Air Limbah. Universitas Curry Press: Cambridge. 